\title{
Sürdürülebilir Kalkınma Vs. Ekolojik Düşünce
}

\author{
DOI: 10.26466/opus.537418 \\ * \\ Hazal Ilgın Bahçeci ${ }^{*}-$ Kemal Görmez ${ }^{* *}$ \\ * Dr. Öğr. Üyesi, Yozgat Bozok Üniversitesi İ̈BF, Yozgat/ Türkiye \\ E-Posta: hazalilgin@gmail.com \\ ORCID: 0000-0003-3967-0960 \\ ** Prof. Dr., Ankara Hacı Bayram Veli Üniversitesi, İ̈BF, Ankara / Türkiye \\ E-Posta: kgormez@gmail.com \\ ORCID: 0000-0001-5662-9543
}

\section{Öz}

1987 yılında yayınlanan Ortak Geleceğimiz, diğer adıyla Brundlant Raporu'nda "bugünün ihtiyaçların gelecek nesillerin ihtiyaçların karşılamasından ödün vermeksizin karşılamak" şeklinde tanımlanan sürdürülebilir kalkınma kavramı, özellikle 1990'lı yıllarla birlikte popüler hale gelerek, neredeyse tüm dünyada hem kalkınma politikalarına hem de çevre politikalarına yön veren hâkim anlayışa dönüşmüştür. Odağında "ekonomik büyüme sağlanırken çevrenin de korunabileceği iddiası" yer alan sürdürülebilir kalkınma anlayışı, endüstriyel kapitalizmin piyasa odaklı anlayışı ile kalkınmanın geleneksel modellerinden kopmaması ve ortaya konduğu zamandan günümüze geçen otuz beş yıl içinde ekolojik sorunlar konusunda bir ilerleme kaydedilmemiş olmasından dolayı önemli eleştirilere maruz kalmaktadır. Bu bağlamda çevreci görüşler içindeki yeri irdelenen sürdürülebilir kalkınmanın, bölgesel ve küresel düzeyde yaşanılan ekolojik sorunların çözümünde başarısız olduğu ve söz konusu sorunların çözümünün, ancak mevcut kalkınma modellerine karşı geliştirilebilecek alternatifler sayesinde üretilebileceği ifade edilmektedir. Literatür tarama metoduyla gerçekleştirilen bu çalışmanın amacı sürdürülebilir kalkınma anlayışının kalkınma ve çevre koruma arasında bir uzlaşı sağlanabileceğine yönelik iddiasının irdelenerek, kavramın ekolojik sorunların çözümündeki yerinin belirlenmesidir.

Anahtar Kelimeler: Ekoloji, ekolojik düşünce, kapitalizm, kalkınma, sürdürülebilir kalkınma 


\title{
Sustainable Development Vs. Ecological Thought
}

\begin{abstract}
The concept of sustainable development, defined as" meeting today's needs without compromising the needs of future generations "in Our Common Future Report, also known as Brundtland Report published in 1987, has become popular especially in the 1990's and has become a dominant understanding that directs both development policies and environmental policies in almost the whole world. The concept of sustainable development, which assumes that the environment can be protected while providing economic growth, focuses on criticism due to the fact that no progress has been made on ecological problems within thirty-five years from the time of its emergence to the present. The aim of this study, which is carried out by the literature survey method, is to determine the place of the concept in the solution of ecological problems by examining the claim that sustainable development approach can be achieved between development and environmental protection.
\end{abstract}

Keywords: Ecology, ecological thought, capitalism, development, sustainable development 


\section{Giriş}

Özellikle 18 yüzyıldan itibaren kalkınma kavramı, ekonomik nedenler dolayısıyla tüm ülkeler için öncelikli bir yere sahip olmuştur. Bu durumda özellikle sanayi Devrimi sonrasında hızla gelişmeye başlayan kapitalist üretim biçiminin sürekli büyümeye dayanan yapısı önemli rol oynamıştır. 1960'lı yılların sonlarına gelindiğinde, kapitalizmin öngördüğü yoğun kaynak kullanımına dayalı ekonomik yapının zorunlu bir sonucu olarak, kalkınmanın doğal kaynaklar ile çevreyi olumsuz yönde etkilediğinin gün yüzüne çıkması ve büyüme odaklı kalkınma anlayışının sürdürülemez hale gelmesi, çevre ve kalkınma ilişkisinin tekrar ele alınmasının gerekliliğini ortaya çıkarmıştır.

Çevre ve üretim konusunun rasyonel bir şekilde çözümü için, "büyümenin doğal kaynakların gelecekte de kullanılmasına imkan tanıyan bir hızla sürdürülmesini sağlayabilmek" ya da "doğal kaynakları, büyümeyi gelecekte de sürdürmeye imkan sağlayacak bir şekilde korumayı sağlamak" esasında bir büyüme stratejisi ortaya konmuş (Yaylı, 2011, s.923) ve sürdürülebilir kalkınma anlayışı bu şekilde ortaya çıkmıştır.

Günümüzde yaşanılan ekolojik bunalımın en önemli nedeninin kapitalist üretim biçiminin öngördüğü ekonomik faaliyetler olmasına karşın, sürdürülebilir kalkınmanın bu açıdan ortaya koyduğu modellerin mevcut ekonominin büyüme, tüketim, fayda-maliyet, rekabet gibi temel yapılarında esaslı bir değişiklik öngörmemesi (Kılıç, 2012, s.201), sürdürülebilir kalkınma anlayışının ciddi şekilde eleştirilmesine neden olmaktadır.

Çalışmada sürdürülebilir kalkınma anlayışının mevcut üretim biçimiyle olan ilişkisini kavrayabilmek açısından öncelikle kapitalizmin nasıl bir üretim biçimi olduğu ortaya konacak, ardından sürdürülebilir kalkınma kavramının ortaya çıkışını hazırlayan ekonomik ve politik koşullara kalkınma modeinin dünya genelinde geçirdiği dönüşüm çerçevesinde değinilecek ve nihayet sürdürülebilir kalkınma kavramının üzerinde şekillendiği temel kavramların irdelenmesi yoluyla anlayışın ekolojik sorunların çözümündeki potansiyel yeri tartışılacaktır. 


\section{Bir Üretim Biçimi Olarak Kapitalizm}

Ortaya çıkışı Merkantilizm ve Fizyokrat düşüncenin etkisi ile tarım ve ticaretteki ilerleme ve yeni ticaret yollarının keşfine dayanan kapitalizm; 16 . ve 18. yüzyıllarda İngiliz sanayisinde yaşanan gelişmeler ile sistemleşerek yerleşmeye başlayan, sanayi devrimi sonrasında gelişimi hızlanan ve nihayet 21. yüzyılda küreselleşme sürecinin etkisiyle daha organize ve yayılmacı bir hal alan (Çelik ve Dağ, 2017, s.51), temelde özel mülkiyete ve özel teşebbüse dayanan ekonomik bir sistemdir. Ekonomik faaliyetlerin büyük ölçüde kar amacı güden özel bireyler ya da özel kuruluşlar tarafından yürütüldüğü, dolayısıyla, üretim araçlarının da büyük ölçüde bireyler tarafından sahiplenildiği bir sistem olarak kapitalizm, üretim araçlarının özel mülkiyetine sahip olanların, bunlar hakkında sınırsız tasarrufunu öngörmektedir.

Ekonomik bir sistem olarak kapitalizm, özel mülkiyet, rekabet, maksimum kar motivasyonu, ileri teknoloji ve sermayenin genişletilmiş yeniden üretimi üzerinden ilerler. Bu haliyle kapitalizmin, insanla toplum, doğayla toplum ya da insanla doğa arasındaki ilişkinin radikal bir değişikliğe uğramasında başlıca sorumluluğu üstlendiği ifade edilmelidir.

Söz konusu radikal değişimin ortaya çıkması bağlamında sistemin can alıcı noktası ise yenilik üretiminin kullanım değeri için değil, değişim değeri için yapılıyor olmasıdır. Bu şekilde üretimin nihai amacı, insan ihtiyaçlarını karşılamaktan ziyade değişim değeri yaratmak haline gelmiştir. Sistem içinde değişim değeri üretmek, diğer bir deyişle pazar için üretmek üzerindeki vurgu, kar elde etmenin yolunun buradan geçmesinde yatmaktadır. İlk bakışta sistemin nihai hedefinin kar elde etmek olduğu düşünülse de sistemin devamlılığı için üretim süreci sonucunda elde edilen karın yeniden yatırıma yönlendirmesi daha hayatidir Çünkü "kapitalist sistemin üretim mekanizmasının istenen düzeyde gerçekleşebilmesi için bir sermaye birikiminin varlığı; oluşan sermaye birikiminin etkin bir üretime dönüşebilmesi için de sermaye birikiminin devamlılığ 1 esastır"(Çelik ve Dağ, 2017, s.54). Böylece kapitalizm koşullarında üretim "üretim için üretim" ya da "sermayenin yeniden üretimi" biçimini almıştır (Başkaya, 2002, s.12).

Kapitalist üretim biçiminde sistemin dinamizmini sağlayan başlıca unsur rekabettir. Rekabet, fiyat mekanizmasının sağlıklı bir şekilde işleyerek 
istenen seviyede tutulabilmesi, kaliteli ürünlerin ortaya çıması ve toplumsal faydanın arttırılması açısından önemlidir. Bu çerçevede sistem içinde rekabetin; kaynakların en karlı şekilde kullanılmasını, yeni buluşlarla birlikte sistemin dinamik kalmasını, yeni tekniklerin kullanılmasını, üretimin tüketici tercihlerine uygun bir şekilde gerçekleştirilmesini ve başarı oranının artmasını sağladığı varsayılmaktadır (Çelik ve Dağ, 2017, s.53). Bunun anlamı, üretim araçlarına sahip olan sermaye sahiplerinin sistem içinde ayakta kalabilmek için rekabetçi konumlarını korumalarının ve bunu her seferinde daha ileri teknolojiye sahip olarak güçlendirmelerinin bir zorunluluk olduğudur. Diğer bir ifadeyle sistem içinde var olabilmek için sürekli büyümek gerekmektedir. Bu şekilde sistem devamlılı̆̆ için sürekli üretmeyi ve üretileni de satmayı zorunlu kılmakta ve bir "üretim çılgınlığı" ortaya çıkmaktadır (Başkaya, 2002, s. 12). Söz konusu tüketime dayalı büyüme ekonomisini ayakta tutan temel motivasyon ise bireysel maddi refahı maksimize etme çabasıdır. $\mathrm{Bu}$ çaba, giderek artan dünya nüfusu ve gelişen teknolojiyle ekonominin sürekli büyümesini sağlamakla birlikte söz konusu büyüme, büyük ölçüde hem bireysel hem de toplumsal maddi gereksinimlerin sayısal olarak sürekli arttırılması yoluyla gerçekleştiğinden, yaşam kalitesini sübjektif olarak belirleyen bir anlayışın da ortaya çıkmasına neden olmuştur (Kıllıç, 2012, s. 214).

Sistem içinde üretimin amacının kullanım değeri değil de değişim değeri yaratmak yoluyla genişletilmiş yeniden üretimi sağlamak olması, araçlar ve amaçların yer değiştirmesi; dolayısıyla toplum ve ekonomi arasındaki ilişkinin yeniden tanımlanması anlamına gelmiştir. Doğal olarak insan ihtiyaçlarını karşılamak ve toplum yararını sağlamak adına yapılması gereken bir faaliyet olan üretimin bu şekilde hedefinden sapması, ekonominin toplumun hizmetinde olduğu bir durumdan, toplumun ekonominin hizmetine girdiği bir duruma geçişi ifade etmektedir. Bu şekilde piyasa, bireyin ihtiyaçlarına göre düzenlenen bir yapı olmaktan çıkarılmış ve bireyin piyasanın ihtiyaçlarına göre şekillendirilmesi süreci başlamıştır. Bu süreçte ise her birey kapitalist üretim biçiminin devamlılığ için üzerine düşen rolü oynayan birer aktör haline getirilmiştir (Kılıç, 2012, s.213).

Söz konusu süreçte sadece toplum ya da bireyler değil, doğa da kapitalizmin hizmetindeki bir aktör haline gelmiştir. Böylece kapitalist 
üretim biçiminde üretimin kullanım değeri kaygısı olmadan yapılması gerekliliğinin doğal bir sonucu olarak doğa, sonsuz şekilde kullanılabilir sayılmış ve bir meta konumuna indirgemiştir. Doğanın meta haline gelmesi ise, rekabet üzerine kurulu bu sistemin verimliliğini arttırabilmesi için üretimin her ileri aşamasının doğal çevre tahribatının ve ekolojik riskin büyümesi pahasına gerçekleşmesi anlamını taşımakta olup, bu anlamda kapitalist üretim biçiminin devamlı olabilmesi için her açıdan tahripkar olması bir zorunluluk gibi görülmektedir (Başkaya, 2002, s.14).

\section{Büyüme Odaklı Kalkınma Anlayışının Ortaya Çıkışı ve Kapitalizmin Krizleri}

18. yüzyıla kadar günlük konuşma dilinde kalkınma(gelişme), bir nesnenin ya da organizmanın gizilgüçlerini, doğal, tamamlanmış ve eksiksiz bir biçime ulaşıncaya kadar harekete geçiren bir süreci ifade etmiş ve bitkiler ile hayvanların doğal bir şekilde büyüdükleri açıklanırken bu kelime biyolojik bir metafor olarak kullanılmıştır. 1759 yılında Caspar Friedrich Wolff'un hem bitkilerde hem de hayvanlarda embriyonik gelişimi, hücrelerin katmanlarını içeren bir süreç olarak tanımlaması ile 1859'de Charles Darwin'in Türlerin Kökeni adlı eseriyle Evrim Teorisi'ni ortaya atması arasında geçen süreçte kalkınma(gelişme), canlıyı uygun biçimine ulaştıran bir dönüşme kavramı olmaktan çıkarak, "canlıyı evrimden geçirerek daha mükemmel bir biçime ulaştıran dönüşme" kavramını karşılar hale gelmiştir. Böylece biyolojik metafordan toplumsal alana geçiş 18. yüzyılın son çeyreğinde gerçekleşmiştir. Hegel ve Marx gibi düşünürlerin bilimsel çalışmalarıyla tarihsel gelişmenin yasalarının da kaçınılmaz doğa yasalarına benzediğine yönelik bir yaklaşım ortaya çıkmış, Sanayi Devrimi'nin getirdiği makineleşme ve teknoloji ilerlemeyle birlikte oluşan sermaye birikimiyle birlikte kalkınmanın zorunlu ve kaçınılmaz bir yazgı olarak tarih sahnesine çıkışının temeli atılmıştır. Ardından gelen süreçte birçok toplumsal yaşam biçiminden sadece birisi olan endüstriyel üretim tarzının, tek biçimli toplumsal evrim çizgisinin son evresi olarak tanımlanmış ve tarihin kalkınma metaforuyla yeniden biçimlendirilmesi süreci bu şekilde başlamıştır (Estava, 2007, s.21,22).

Uygarlık seviyesinin üretim seviyesiyle ölçülür duruma gelindiği bu süreçte "kalkınma metaforu, değişik kültürlere sahip toplumları kendi 
toplumsal yaşam biçimlerini tanımlama olanağından yoksun bırakarak her yönüyle Batılı tarih yorumuna küresel bir egemenlik kazandırmıştır"(Estava, 2007, s.22). Böylece zaman içinde kalkınmanın önüne farklı kavramlar eklenerek dönemine göre farklı paradigmalar yaratılmış ${ }^{1}$ ama her dönemde kalkınma metaforunun popülaritesi için tek bir ön koşul var olmuştur, s.Az gelişmişliğin tanımlanması.

$\mathrm{Bu}$ süreç, kapitalist üretim biçiminin, özellikle Sanayi Devrimi sonrasında çeşitli biçimler alarak günümüze kadar ulaşmasıyla kol kola ilerlemiştir. Sanayi Devrimi'nin hemen öncesinde hem merkantilizmin hem de yeni ticaret yollarının keşfiyle birlikte sermaye birikiminin hız kazanması, bireylerin yanı sıra devletlerin de ciddi şekilde güç kazanmasına sebep olmuştur. Büyük sermaye sahibi ülkelerin bu gücü kullanarak yoksul ülkelerin kaynaklarını paylaşma yarışına girişmesiyle söz konusu yoksul ülkeler sömürge ülkeler haline getirilmiş; bu şekilde kapitalizmin sistematik bir üretim biçimi haline gelmesi için gerekli sermaye artarak birikmeye başlamıştır. Bu şekilde yeni bilimsel buluşların sanayiye aktarılması için gereken finansman sağlanarak sanayi devriminin gerçekleşme koşulları hazırlanmıştır (Çelik ve Dağ, 2017, s.57). Sanayi devrimi sonrasında üretim tekniklerinde ortaya çıkan yenilikler ile birlikte daha az maliyetle daha çok ürün elde edilmeye başlanmasıyla ise bu ürünler için yeni pazar arayışı doğmuş ve doğrudan sömürgecilik üzerinden ilerleyen ekonomik sistem II. Dünya Savaşı'na kadar devam etmiştir.

II. Dünya Savaşı sonrası sömürgeciliğin doğrudan biçiminin tasfiye edilmesi², ekonomik sistem içinde kalkınmanın bir motto olarak bir retorik biçiminde öne sürülmesi için önemli bir milat olmuştur. Söz konusu tasfiye sürecinde uluslararası sistemin yeniden düzenlenmesi gereği hâsıl olmuştur. Bu yeni sistem gelişmiş ülkeler tarafından az gelişmiş ya da gelişmekte olan ülkelere yönelik olarak başlatılan ekonomik ve teknik

\footnotetext{
${ }^{1}$ Örneğin; katılımcı kalkınma, bütünleştirilmiş kalkınma, içeriden kalkınma vb. Ayrıntılı bilgi için bkz.: Gustava Estava(2007), "Kalkınma", Kalkınma Sözlüğü: Bir iktidar Olarak Bilgiye Giriş, Ed. Wolfgang Sachs, Çev. Oktay Etiman, Ankara: Maki Basım, 17-50

2 Sömürgeciliğin doğrudan biçiminin tasfiye edilmesinin altında yatan temel faktör, çok büyük kıtaların birkaç sömürgeci gücün hâkimiyeti altında olmasının, sermayenin her yere ulaşmasının önünde önemli bir engel teşkil etmesinden dolayı artık sermaye tarafından kabul edilebilir bir durum olmaktan çıkmasıdır. Ayrıntılı bilgi için bkz. Fikret Başkaya (2002), "Kalkınma: Bir Efsanenin Sonu, Özgür Üniversite Forumu, S.19, s. $16-20$
} 
yardım temelli borçlanma politikasına dayalı, büyüme odaklı kalkınma anlayışı temelinde kurulmuştur. "Kalkınma paradigmasının temel savlarından olan büyüme sağlandıkça toplumsal refahın artacağı ve daha eşitlikçi bir biçimde dağılacağına"(Buyruk, 2016, s.113) yönelik argümanlar bu dönemde inşa edilerek günümüze ulaşmıştır Bu durum, ülkeler arasında yaşanan büyüme odaklı sosyo-ekonomik rekabetin başlangıcını da teşkil etmekte olup; günümüzde dünya çapında ekolojik dengenin korunması konusunda gösterilen çabaların önünde de önemli bir engel olduğu ifade edilmelidir.

Büyüme odaklı kalkınma anlayışının yol göstericiliğinde 1970'li yıllara gelindiğinde batılı erken kapitalistleşmiş ülkelerin refah düzeylerini koruma noktasında iki temel politik ve ekonomik krizle karşı karşıya kaldığı görülmektedir. Bunlardan ilki kapitalizmin kendisine içkin doğasından kaynaklanan büyüme krizidir ${ }^{3}$. Bu krizin birincisi; kapitalizmin genel sermaye birikimi krizi, ikincisi ise Keynesyen politikaların yan etkisi olarak ortaya çıkan yoksulluk ve çevresel bozulmalar olmak üzere iki temel görünümü bulunmaktadır. Bu sorunlar karşısında ya 1972 yılında Roma Kulübü tarafından ortaya atılan "sıfır büyüme” yaklaşımı benimsenerek bu dönemde palazlanmaya başlayan toplumsal hareketlerin dillendirdiği piyasaya dayanmayan yaşam biçimlerine yönlenilecek ya da, doğanın kullanımı ile ekonomik büyüme ilişkisine piyasa ekonomisi içinde bir olanak yaratılarak sermaye birikim krizlerini aşacak yeni politikalar oluşturulacaktı (Özlüer, 2007, s.5). Pek tabii, ikinci tutum benimsendi.

Dönemin ikinci politik ve ekonomik krizi ise yukarıda bahsedilen büyüme odaklı kalkınma anlayışının sürdürülemez hale gelmesiyle ortaya çıkmıştır. Büyüme odaklı kalkınma anlayışı temelinde yürütülen, ekonomik ve teknik yardıma dayalı borçlanma politikası az gelişmiş ve gelişmekte olan ülkelerde toplumsal, siyasal ve ekonomik alanlarda pek çok sorunun ortaya çıkmasına neden olarak yürütülemez bir hal almıştır. Söz konusu politikalarla ilgili ülkelerde ekonomik büyüme sağlanmasına rağmen gelir adaletsizliğinin ve beraberindeki siyasal sorunların artması

\footnotetext{
${ }^{3}$ Söz konusu krizler, kapitalizmde üretimin toplumsallaşmasına ve toplumsal ölçekte planlanma gerekliliğine karşın her bir sermayedarın kendi çıkarını düşünerek hareket etmesinin ortaya çıkardığı çelişkilerin bir sonucudur. Ayrıntılı bilgi için bkz; Karl Marx (2015), Kapital, Çev.Mehmet Selik, C. I ve C. II, istanbul: Yordam Kitabevi
} 
bu durumun en önemli göstergesi olmuştur. Böylece mevcut kalkınma anlayışında bir takım değiş̧ikliklere gidilmesinin gerekliliği ortaya çıkmış ve ekonomik büyüme dışında başka bir takım somut göstergeler belirlenerek bugünkü kalkınma ekonomisinin temel ilgi alanları 1970'li yıllarda bu şekilde belirlenmiştir (Hirschman, 2015, s.49).

Mevcut kalkınma anlayışında yaşanan bu değişim, o güne değin kalkınma ekonomisinin tek kıstası olan kişi başına gelirin yerini, beslenme, sağlık, yiyecek, konut ve eğitim gibi her biri farklı uzmanlıklar gerektiren kısmi hedeflere bırakması ve böylece temel ihtiyaçlar söyleminin ortaya atılmasıyla sonuçlanmıştır. Bu şekilde eşitsizlik olgusu, "eksik tüketim" ya da "üretimin bölüşümünün adaletsizliği şeklinde yeniden inşa edilirken(Özlüer, 2007, s.5), üretim tarzından ve üretim sürecinden kaynaklanan toplumsal eşitsizlikleri arka plana iten bir eğilim ortaya çıkmıştır. Bu eğilimin yarattığı yeni yaklaşıma göre, yoksulluk ve toplumsal eşitsizlikler temelde gelir dağılımı adaletsizliği ve bölüşüm sorunundan başka bir şey değildir ki bu da, sorunun kaynağı olan kapitalist üretim biçiminin sürekli büyüme mottosunun yok sayılması anlamına gelmektedir. $\mathrm{Bu}$ süreç, sermayenin genişletilmiş yeniden üretimi olan büyümenin gayri safi milli hasıla ya da milli gelirle ölçülmesi ve söz konusu büyümenin de kalkınma ile özdeş sayılmasını beraberinde getirmiştir. Böyle bir anlayış ise amacın kullanım değeri yaratmak değil de, sermayenin genişletilmiş yeniden üretimini sağlamak adına değişim değeri yaratmak olduğu kapitalizmde, neyin, neden ve nasıl üretildiği sorularının boşlukta kalması anlamını taşımaktadır. Bu çerçevede örneğin bir ülkede tank, savaş uçağ 1 ve kara mayını üretimlerinin beş kart artması, topumun refah artışına hiçbir katkı sağlamadığı halde, gayri safi milli hasılanın da aynı oranda büyümesi anlamına gelmekte ve bir kalkınma göstergesi sayılabilmektedir. Bu bağlamda, kapitalist üretim biçimiyle çok yüksek büyüme oranlarına ulaşmanın mümkün olduğu ancak bu büyümenin otomatik olarak toplumsal refahın iyileşmesi anlamında kalkınma üretmesinin mümkün olmadığı göz ardı edilmemesi gereken bir gerçektir (Başkaya, 2002, s.21). İşte sürdürülebilir kalkınma anlayışı, böyle bir ekonomik ve politik yeniden düzenleme sürecinin ekseninde ortaya çıkmıştır. 


\section{Kalkınma ve Çevre Korumayı Uzlaştırma Denemesi Olarak Sürdürülebilir Kalkınma}

Uluslararası arenada kalkınma konusunda yürütülen tartışmaların seyri, Batı ülkelerindeki siyasi duyarlılıkların geçirdiği dönüşümle de yakından ilişkilidir. Ekonomik kriz yaratma eğilimi kapitalizmin özgün karakteristiği olmasına rağmen, halihazırda hızla büyüyen ekolojik tahribatın da ekonomik krizlerle eş zamanlı ilerleyen, kapitalizmin ikinci krizi olduğu ifade edilmelidir. Çünkü kapitalizmin dönemsel olarak kendine özgü krizlerini yaratan acımasız kar arayışı, ekolojik krizin de çıkış noktasıdır (Magdotf, 2002, s.108). Bu çerçevede sürdürülebilir kalkınmanın kullanıma girmesi esas olarak bir şeylerin sürdürülemez olma kaygısıyla ilgili olup; ekolojik krizin yarattığı ekolojik yıkım ve buna bağlı olarak ekolojik düşüncenin gelişerek yaygınlaşmaya başlamasıyla doğrudan bağlantılıdır.

\subsection{Sürdürülebilir Kalkınma Kavramına Doğru}

1960'lı yılların sonlarına doğru batı toplumlarının çoğu öğrenci hareketleri ve diğer bazı hareketlerle çalkalanırken, özellikle barış hareketleri, kadın hareketleri ve anti-nükleer hareketler ön plana çıkmıştır. $\mathrm{Bu}$ süreçte yayınlanan çevre ile ilgili araştırmalar ve eserler, giderek yükselen eylem dalgasının tüm kesimleri kapsamaya başlamasında ve ekolojik bir muhalefetin oluşmasında önemli bir rol üstlenmişlerdir (Görmez, 2018, s.58).

1962 yılında Rachel Carson'un Silent Spring (Sessiz Bahar) adlı eseri, dikkatleri mevcut sanayileşme süreçlerinin çevreye verdiği zararlar üzerine çekerek Batı dünyasında büyük yankılar uyandırmıştır. Bunun yanı sıra 1968 yılında kurulan Roma Kulübü'nün, Massachusetts Teknoloji Enstitüsü'ne (MIT) yaptırdığı bir araştırmanın, 1972'de Ekonomik Büyümenin Sınırları(Limits to Growth) adıyla yayımlanması, ekonomik kalkınma ve çevre arasındaki güçlü ilişkiyi gözler önüne sermiş; mevcut kalkınma politikalarının devam etmesi durumunda, ortaya çıkacak hammadde kıtlığı ve artacak çevre sorunları nedeniyle insanlığın yok olma tehdidi ile karşı karşıya kalacağı belirtilmiştir (Meadows vd., 1972, s.185-197). 1973 yılında yayınlanan Küçük Güzeldir(Small 
is Beautiful) isimli eserinde E. F. Schumacher'in, "doğal kaynakların, mevcut ekonomik yapıda kullanılan sermayenin aslında büyük bir kısmını teşkil etmesine rağmen, maliyet hesaplamalarına gerektiği gibi dâhil edilmemesi, üretim sorununun çözülmüş olduğu inancı, ihtiyaçların sonsuzluğu varsayımı, sınırsız ekonomik büyüme düşüncesi ile bireysel ve toplumsal açgözlülüğün insanlığı büyük bir felakete sürüklediğine" (Bozlağan, 2005, s.1016) yönelik vurgusu, dünyada egemen olan ekonomik paradigmanın yeryüzüne ve insanlığa verdiği zararların gündeme gelmesini sağlayan bir diğer etmen olmuştur.

Ekolojik bunalımın yoğun biçimde tartışılmaya başlandığı bu süreçte, çevrenin korunmasının ve kalkınmanın birbirini dışlamayabileceğine yönelik bir algının yaratılmasının gerekliliği ortaya çıkmış ve bu algının yerini bir anlayışa bırakması için uluslararası kuruluşlar önemli roller üstlenmişlerdir. 1972 yılında Stockholm'de toplanan, çevre konusunun uluslararası gündeme ilk kez girdiği Birleşmiş Milletler İnsan Çevresi Konferansı, söz konusu anlayışın ortaya çıkması için önemli bir zemin hazırlamıştır. Zengin ve yoksul ülkeler ayrımına gidilmeksizin küresel çevre sorunlarının boyutlarına dikkat çekilen ve bu çerçevede kalkınma sorununun da ayrıntılı bir şekilde ele alındığ 1 konferansta, tehdidin tüm insanlığa yönelik olduğu kabul edilerek sorumluluğun paylaşılması konusunda uzlaşmaya varılmıştır (Kaplan, 1999, s.122-123). Yüzden fazla ülkenin katıldığı konferans sonunda yayınlanan deklarasyonda (United Nations, 1972, s.70);

- İnsanın, kendisini fiziki anlamda besleyen ve ona entelektüel sosyal, ahlaki ve manevi gelişimi için fırsat veren çevrenin hem yaratıcısı hem de yok edicisi olduğu,

- İnsanın çevresinin korunmasın ve geliştirilmesin hem insanlığın daha iyi yaşam sürmesi hem de ekonomik gelişmeyi etkilemesi açısından önemli olduğu ve bu anlamda çevreyi korumanın bütün insanların ve hükümetlerin görevi olduğu,

- İnsanın sürekli bir şeyleri deneyimlediği; keşfettiği, icat ettiği, yarattığı ve ilerlemeye devam ettiği vurgulanarak, hayatını iyileştirmek ve ekonomik kar elde etmek amacıyla çevresini tahrip ettiği ve kirlettiği, 
- Gelişmekte olan ülkelerde çevresel sorunların çoğunun az gelişmişlikten kaynaklandığı, gelişmiş ülkelerdeki çevre sorunlarının ise genellikle sanayileşme ve teknolojik gelişme ile ilgili olduğu belirtilmiştir.

Bu çerçevede olarak deklarasyonda "insanın bugünkü ve gelecek nesiller için çevreyi korumak ve geliştirmek adına ciddi bir sorumluluğu olduğu" (United Nations, 1972, s.4) ifade edilerek gelişmişlik farkları göz önünde bulundurulmadan ve gelişmiş ülkelerden yana özel bir sorumluluk alanı tanımlanmadan çevreyi koruma görevi doğrudan insana verilmiştir. İzleyen maddelerde ise bu korumanın sınırsız olamayacağı, kalkınmanın önemi vurgulanarak açıklanmaya çalışılmıştır. Buna göre "insana uygun bir yaşam ve çalışma çevresini sağlamak ve hayat standartlarını iyileştirmek için ekonomik ve sosyal kalkınma şarttır" ve "ülkelerin çevre politikaları, gelişmekte olan ülkelerin bugünkü ve gelecekteki kalkınma potansiyelini destekleyecek ve olumsuz etkilemeyecektir" (United Nations, 1972, s.4). Bunun anlamı, bugünkü ve gelecek nesiller için çevrenin korunmasının ancak, kalkınma amacının gerekliliklerine engel teşkil etmediği ölçüde sağlanabilir olduğudur. Konferansın uluslararası alanda insan-çevre ilişkileri konusunda ciddi bir kamuoyu oluşturduğu ve kendisinden sonra gerçekleştirilecek olan toplantılara öncülük ettiği gerçeği göz önünde bulundurulmakla birlikte, deklarasyondaki ifadelerde insanın, toplumsal karakterinden soyutlanarak doğaya müdahale eden tekil bir varlık şeklinde ele alındığı görülmektedir. Bu bağlamda insan, çevre sorunlarının başlıca sorumlusu olarak gösterilmiş ve kapitalist üretim biçiminin yarattığı esas sorunlar göz ardı edilmiştir. Doğanın yıkımından her ülkenin eşit şekilde sorumlu tutulacağ1 söylemi de bu algının pekiştirilmesinde önemli bir görev üstlenmiştir (Özlüer, 2007, s.6).

\subsection{Sürdürülebilir Kalkınma Nedir?}

Sürdürülebilir kalkınma kavramının ilk kez ortaya atılması, 1983 yılında Norveç başbakanı Brundtland başkanlığında kurulan Birleşmiş Milletler Çevre ve Kalkınma Komisyonu'nun 1987 yılında BM Genel Kurulu'na sunduğu Ortak Geleceğimiz Raporu'yla birlikte gerçekleşmiştir. Sürdürülebilirlik ve kalkınma kavramlarını bağdaştırmaya yönelik 
tartışmanın çok daha önce başlamış olmasına rağmen kavramın resmi olarak benimsenmesi kapitalizmin borç kriziyle hemen hemen aynı döneme denk gelmektedir ${ }^{4}$ (Cleaver,2002, s.57).

Raporda "Bugünün ihtiyaçlarını gelecek kuşakların da kendi ihtiyaçlarını karşılayabilme olanağından ödün vermeksizin karşılamak" şeklinde tanımlanan sürdürülebilir kalkınmayla yalnızca çevre ve ekonomi arasındaki İlişkiye vurgu yapılmadığı, aynı zamanda kavramın toplumsal, siyasal ve kültürel boyutlarının da bulunduğu ifade edilmiştir (Dünya Çevre ve Kalkınma Komisyonu, 1987, s.71). Bu çerçevede kavramın dört temel üzerine inşa edildiği görülmektedir: Yoksulluk, temel ihtiyaçlar, teknolojik örgütlenmenin düzeyi ve gelecek kuşaklar.

Yoksulluğun "temel ihtiyaçların karşılanamaması" şeklinde tanımlandığı; temel ihtiyaçların da yiyecek, giyecek, barınak ve iş bulma ihtiyaçları şeklinde sıralandığı raporda "yoksulluğun ve eşitsizliğin yaygın olduğu bir dünyanın her zaman ekolojik ve diğer krizlere eğilimli olacağı" vurgulanmış ve böylece yoksulluğun ve eşitsizliğin altı çizilmiştir. Bu şekilde yoksulluğa bir yandan kalkınma ile alt edilmek istenen en büyük kötülük anlamı addedilirken bir diğer yandan da yoksulluğun standartlaştırılmaya çalışıldığı görülmektedir. Ülke, toplum ve kültür farklılıkları göz önünde bulundurulmadan tüm dünyada tek ve bilimsel bir yoksulluk tanımının geçerli kılınmaya çalışılarak belli bir gelire ve yaşam standardına ulaşamayan insan ve toplulukların yoksul olarak kabul edilmesi sürdürülebilir kalkınma söylemi için zorunlu bir ön koşuldur (Şahin, 2004, s.197).

Bu şekilde 1970'li yıllarla birlikte yoksulluk gündelik hayatta yeni bir çağrışım yapmaya başlamış ve yoksulluğun insani özelliğinin içeriği tamamen değişmiştir. Bundan böyle yoksulluk, bireyin ihtiyaçlarının gerekli olan mallar ve hatta gerekli olan hizmetler bakımından ölçüsünü ifade eder hale gelmiş ve para aracılığıyla eksiksiz insan olmak için gereken maddeleri satın alamamak olarak tanımlanmıştır (Illich, 2007, s.168). Kapitalist üretim biçimi bireylere, her zaman talep edilecek yeni ürünler sunarak onları, öncelikle malların tüketicisi pozisyonuna sokmaktadır. Sistemin devamlılığının sağlanabilmesi için pazarda, her defasında bir

${ }^{4}$ Brundtland Komisyonu'nun çalışmalarına başladığı 1983 yılı, Meksika'nın iflasını açıklamasından yaklaşık bir yıl sonrasına denk gelmektedir. Bu süreç çalışmanın ikinci başlığında daha ayrıntılı olarak ele alınmıştır. 
öncekinde daha fazla tüketilecek mal bulunması gerekmektedir. Yoksulluk tanımının bu şekilde bilimsel standartlara oturtulması yoksulluğun, tüketilmesi mümkün hale getirilen ürünlerin kitleler tarafından talep edilmesine karşın, bu talebin karşılanamaması olarak görülmesine neden olur ve talep edilebilecek söz konusu ürün ya da hizmetler hazır yiyecekten asfalt yola, standart tatil paketlerinden sezaryenle doğum yapmaya kadar değişebilir (Şahin, 2004, s.198). Bu açıdan kerpiç bir evde yaşayan bir insanın, apartmanda yaşayan bir insandan daha yoksul olduğu değerlendirmesi yapılabilir. Böylece bireylerde bir yoksulluk algısı üretilir ve pekiştirilir. Bu şekilde farklı üretim tarzlarında, kültürel düzeylerde ya da toplumsal yaşam biçimlerindeki insanların, piyasadaki bir ortalama soyut ihtiyaçlar sahibi bireye göre konumlandırıldığı ve yaşamın niteliğinin gözetilmeden yoksulluğun mallara niceliksel olarak sahip olabilmeyle ölçüldüğü bir düzlem yaratılarak kapitalist büyümenin kuramsal temelleri sağlamlaştırılmıştır (Özlüer, 2002, s.7). Raporda yer alan "Eğer gelişmekte olan ülkeler dünyasının büyük kısmı ekonomik, sosyal afet ve çevre felaketlerinden kurtarılacaksa, global ekonomik büyümenin yeniden canlandırılması şarttır. Pratik açıdan bunun anlamı, hem sanayileşmiş hem de gelişmekte olan ülkelerde daha hızlı bir ekonomik gelişme, gelişmekte olan ülke mallarının piyasalara ulaşmasında daha fazla serbesti, daha düşük faiz oranları, daha çok teknoloji transferi ve hem imtiyazlı hem de ticari olarak çok daha büyük bir sermaye akımı demektir"(Dünya Çevre ve Kalkınma Komisyonu, 1987, s.123) ifadeleri ve ortaya konan yoksulluk algisı bize raporun, yoksulluğun ortadan kaldırılmasını kapitalist sermaye birikiminin gelişimine bağladığını göstermektedir. Açıktır ki, mevcut kapitalist üretim biçiminde sürdürülebilir kalkınma, sürdürülebilir kapitalizmle hemen hemen aynı anlama sahiptir.

$\mathrm{Bu}$ kapsamda raporda sunulan yoksulluk tanımının ana öğesi olan temel /asgari ihtiyaçlar söyleminin yarattığı ihtiyaçlar kümesini de ele almak gerekmektedir. Söz konusu ihtiyaçlar kümesinin, belli bir yaşam biçiminin ve kültürünün ürünü olması bir yana, yaratılan yoksulluk tanımı ve buna bağlı olarak ortaya konan temel ihtiyaçlar söylemiyle, toplumsal eşitsizliğin ve adaletsizliğin temelinde üretimin yanlış örgütlenmesinin yattığı gerçeği arka plana itilir ve bu, ekonomik değeri olmayan 
tüm toplumsal varlık biçimlerinin değersizleştirilmesi yoluyla gerçekleştirilir:

“Değersizleştirme süreci, becerileri yokluklara, ortaklaşa kullanılanı kaynaklara, erkekleri ve kadınları metalaştırılmış emeğe, geleneği yüke, bilgeliği cehalete, özerkliği bağımlılığa dönüştürür. İnsanların isteklerinin, becerilerinin, umutlarının, birbirleriyle ve çevreleriyle kurdukları ilişkilerinin somutlaştığı özerk eylemler değersiz kılınınca, sadece piyasa aracılığıyla karşılanabilecek ihtiyaçlar haline gelirler"(Estava, 2007, s.38).

Böylece ilgili "temel ihtiyaçlar", insanın mizacını değiştirmiş; aklı ile duygularına yeni bir biçim vermiş ve homo sapiensi, homo miserabilis (yoksul, sefil) haline getirmiştir. Bu haliyle temel ihtiyaçlar, kalkınmanın biraktığı en sinsi miras olarak değerlendirilmektedir (Illich, 2007, s.158).

Raporda göz çarpan bir diğer önemli husus, temel ihtiyaçların karşılanmasının ancak tam büyüme potansiyeline ulaşılmasıyla gerçekleşebileceğine yönelik savdır. Buna göre sürdürülebilir kalkınma, bu ihtiyaçların karşılanamadığı yerlerde ekonomik büyümeyi gerektirir ancak, tam büyüme koşullarında da yoksulluk var olmaya devam edebilir. Sürdürülebilir kalkınmanın sağlanabilmesi için ise, hem toplumların üretim potansiyellerinin arttırılması hem de herkese eşit firsat tanınmasının garanti altına alınması gerekmektedir (Dünya Çevre ve Kalkınma Komisyonu, 1987, s.72). Bu noktada raporun, kapitalist ekonominin sınırsız büyüme ekseninden kopmadığı ve bu büyümenin sağlanabilmesinin de toplumun temel asgari ihtiyaçlarının karşılanmasına bağlı olduğuna yönelik bir varsayımının olduğu görülmektedir (Özlüer, 2007, s.6). Dolayısıyla sürdürülebilir kalkınmanın gerçekleştirilebilmesi için yoksulluğun yayılması, yoksulluğun yayılması için yeni ihtiyaçların tanımlanması, yeni ihtiyaçların hak edilmesi için temel ihtiyaçların karşılanarak en yoksul kategorisinden kurtulunması gerekmektedir ki bu da, söz konusu yoksulluk algısının hiçbir zaman ortadan kalkmaması ve tüm dünyayı kuşatmasıyla mümkündür (Şahin, 2004, s.198).

Tüm bunların yanı sıra raporda söz konusu temel ihtiyaçların hangi yollarla belirlendiği sorusunun net bir cevabı bulunmamaktadır. Bu çerçevede sürdürülebilir kalkınma anlayışının belki de en can alıcı noktası karşımıza çıkmaktadır: Sürdürülebilir kalkınma anlayışı, insanların 
sınırsız ihtiyaçları olduğu buna karşın kaynakların sınırlı olduğu varsayımına dayanmaktadır ki "temel ihtiyaçlar" söylemi de bu varsayımın bir ürünü olarak ortaya atıldığından, aslında baştan itibaren ekolojik düşüncenin karşısında yer aldığı söylenebilir.

Raporda yoksulluk ve temel ihtiyaçlar üzerinden, çevre ve kalınma arasındaki dengenin piyasa koşullarında kurulabileceği açık bir şekilde ortaya konmuş olup, bu noktada teknolojik örgütlülügün kapasitesini artırmanın önemli olduğu ifade edilmektedir. Raporun 5, 7, 8 ve 9. bölümlerinde yenilenebilir enerji sistemleri, kirlenme kontrolü, teknoloji değiş tokuşu gibi konulara yer verilmiştir. Bu çerçevede gelişmekte olan ülkelerdeki bilimsel ve teknolojik kapasiteler arasındaki boşluktan bahsedilerek, biyolojik bilgiyi biriktirme konusunda harekete geçilmesi gerektiği ve biyo-teknolojik kapasitelerinin geliştirilmesi konusundaki çabalara yoğunlaşılması gerektiği ifade edilmiştir (Dünya Çevre ve Kalkınma Komisyonu, 1987, s.121-122). Bir açıdan teknoloji merkezli olduğu söylenebilecek bu yaklaşım, enerji kullanımında yenilenemez enerji kaynaklarının yoğun bir biçimde kullanımından kaçınılarak, yenilenebilir enerji kaynaklarına yönelinmesi ile doğal kaynaklara ve çevreye zarar vermeyen teknolojilerin geliştirilerek bunun için araştırma ve geliştirme faaliyetlerine önem verilmesinin altını çizmektedir (Mengi ve Algan, 2003, s.34). Ancak Özlüer'e göre çevre sorunlarının çözümünde sağlıklı bir adım olarak değerlendirilebilecek bu niyet mevcut şartlar altında anlamını yitirmektedir:

“(...) bu teklif, verili üretim ve tüketim kalıplarını değiştirme perspektifinden beslenmediği ölçüde, sorunu gerçek anlamda çözme potansiyeli barındırmıyor. Atmosferdeki karbon miktarının artmasına neden olan doğal ormanların sanayiye ya da endüstriyel tarım ve hayvancılığa kurban edilmesi, uluslar arası taşımacılık sektörünün her geçen gün büyümesi ve otomobile dayalı bir uygarlığın toplumsal tüketim alışkanlıklarının, üretim tarzındaki değişikliklerle mümkün olabileceğinin hesaba katılmaması, bu tür önerilerin çözüm yolunda alternatif olabilme gücünü zayıflatıyor. Daha genel bir anlamda da şu söylenebilir ki, üretici güçlerin gelişiminin doğası, üretim ilişkileri tarafından belirlenir. Neyin, nasıl, ne kadar, ne için üretildiği hesaba katılmadan üretilen teknolojik alternatifler, piyasadaki enerji desenini çeşitlendirmekten başka bir işe yaramayacaktır" (Özlüer, 2007, s.12). 
Kapitalist büyüme doğanın her seferinde daha yoğun sömürüsüyle mümkündür. Bu yüzden "piyasa ekonomisinin sermaye birikimine dayalı işleyişinin sınırları doğayı da kapsayacak şekilde genişletilmiştir ki bu, kapitalizmin her şeyi metalaştırmaya dönük mantığının zorunlu bir sonucudur" (Özlüer, 2007, s.8). Bu minvalde kapitalist teknolojiyi, onu var eden üretim tarzının bilgisinden ve ideolojisinden ayrı bir yerde konumlandırmak çok gerçekçi bir bakış açısı olmayacaktır. Çünkü burada teknoloji bir yandan, verili üretim tarzının yaşam kültürünü ve yaşama biçimini de örgütlemektedir (Özlüer, 2007, s.8). Üretici güçlerin önemli bileşenlerinden birisi olan doğayı sınırsızca kullanan bir teknolojik gelişme sürecinin yoksulluk ve ekolojik krizlerin çözümünde kilit bir noktada olduğunun belirtilmesi bu noktada bir anlam ifade etmemektedir.

Sürdürülebilir kalkınmanın dayandığı bir diğer önemli söylem/kavram olan "gelecek kuşaklar"ın popüler hale gelmesi ise esas olarak 1970'li yıllarda tüm dünyada gün yüzüne çıan ekolojik kaygılarla ilgilidir. Gelecek kuşaklara karşı sorumluluklarımızın olduğuna yönelik düşünceler bu dönemde palazlanmaya başlayan toplumsal hareketleri iki noktadan hareketle önemli ölçüde etkilemiştir. Öncelikle "başta nükleer teknolojinin ürettiği radyoaktif atıklar olmak üzere, endüstriyel üretimin doğaya bıraktığı muazzam miktardaki atık yükünün, vadesi belirsiz uzun bir gelecek zamana kadar çevrede kalacak ve yaşama ortamını kirletecek oluşu; daha da önemlisi bu atıkların yok ettiği doğal yaşama alanlarının gelecekte yaşayacak insanlara bırakılamayacak olması" (Şahin, 2004, s.197) kaygısıyla insanoğlunun ahlaki sorumluluğu gelecek kuşaklara kadar genişletilmiştir. Söz konusu ikinci nokta ise, doğal kaynaklar söyleminin, doğal kaynakların gelecek kuşaklarla "paylaşılma" düşüncesinin ileri sürülerek kullanılmasıdır. Bu çerçevede sürdürülebilir kalkınmanın büyük ölçüde, doğayı insanın hizmetindeki bir kaynak havuzuna indirgeyen insan merkezci bir anlayış olduğu ifade edilmektedir. Çevre koruma ve ekonomik kalkınmayı uzlaştırmaya çalışan kalkınmacı çevrecilik böylece, ekolojik düşüncenin ve politik akımların ahlaki çıkış noktalarından biri olan gelecek kuşaklara olan sorumluluklarımız düşüncesini, kaynakları gelecek kuşaklarla birlikte kullanma zorunluluğunu gündeme getirerek bir erozyona uğratmış ve kalkınmacı çevreciliğin manifestosuna doğanın tükenebilir bir kaynak olduğu fikrini 
aşılamıştır (Şahin, 2004, s.197).Ortak Geleceğimiz Raporu'nda bu durum şu şekilde ifade edilmektedir:

“...ekonomik kalkınmayı yanında getirecek yeni bir çağın başlayabileceğini görüyoruz. Bu çağda çevre kaynak varlığımızı sürdürebilecek ve genişletebilecek tedbirler alınabilir. (...) ...kararlı bir siyasi tutumun başlaması, çevre kaynaklarının hem insanlığın sürekli ilerlemesine hem de bekasına dönük olarak yönetilmesi (şarttır). (...) ...gerek bu kuşağ1 ve gerekse gelecek kuşakları garantiye almak için gerekli kaynak sağlama kararlarını almanın zamanı gelmiştir." (Dünya Çevre ve Kalkınma Komisyonu, 1987, s.23-31).

Böylece gelecek nesiller için stabilite ve dünya kaynaklarının zenginliğinin sürdürülebilirliğini sağlamak konusunda insanoğlunun etik bir sorumluluğunun bulunduğunun belirtilerek bugünün kuşaklarının ve gelecek kuşakların dayanışmasının öngörüldüğü raporda, mevcut toplumsal ilişkiler içinde dayanışmanın nasıl gerçekleşeceği noktasında bir fikir beyan edilmemiştir ki, esas tartışılması gereken konu budur. Çünkü sürdürülebilir kalkınma anlayışının hedeflerine ulaşabilmesi için sosyal piyasa ekonomisi ${ }^{5}$ olarak kabul edilen mevcut ekonomik ve toplumsal yapının korunması gerektiği ileri sürülmektedir (Kılıç, 2012, s.206). Bugünün kuşakları arasında dahi adil gelir dağılımı mekanizmalarının uygulamaya sokulamadığı bir sistemde, sürdürülebilir kalkınma anlayışının "kuşaklar arasında servet ve gelirlerin paylaşımında genel adalet prensiplerine göre hareket edilmesi"(Kılıç, 2012, s.207) gerekliliğini vurgulaması pek rasyonel gözükmemektedir.

Bölgesel ve küresel düzeyde karşı karşıya kaldığımız ekolojik krizler, endüstriyel kapitalizmin ve kalkınmanın geleneksel modellerinin doğal bir sonucudur. Bunun yanı sıra bu krizler çıplak doğadan (non-human nature) değil; toplum yapısından, davranışlarımızdan ve karşılıklı ilişkilerimizden kaynaklanan toplumsal krizler olarak da görülmelidir. Bu nedenle kalkınma açmazına yönelik her özgün çözüm, endüstriyel kapitalizm modelinin ve bu modelin yarattığı toplumsal yapının doğal sonucu olan sorunları işaret etmelidir (Chodorkoff, 2002, s.113).

\footnotetext{
${ }^{5}$ Kavram ilk olarak ORDO liberallerinden Alfred Müller-Armack tarafından ortaya atılmış olup, amacı piyasada özgürlük ve sosyal eşitlik ilkelerini bağdaştırmak olan ekonomik düzeni oluşturmaya yönelik bir programı ifade etmektedir.
} 


\section{Sonuç}

Esas olarak dünya çapında gerçekleşen önemli bir ekonomik ve politik yeniden düzenleme sürecinin bir sonucu olarak ortaya atılan ve uluslararası örgütler tarafından yürütülen birtakım ciddi hazırlıklardan sonra Ortak Geleceğimiz Raporu'yla tarih sahnesine çıkan sürdürülebilir kalkınma paradigması, 1987 yılından günümüze neredeyse tüm ülkelerin çevre politikalarına yön vermektedir. Bu sürecin temel belirleyicileri ise Stockholm Çevre Konferansı'nı izleyen süreçte gerçekleşen Rio Zirvesi, Johannesburg Sürdürülebilir Kalkınma Dünya Zirvesi ve Habitat gibi uluslar arası konferanslar olmuş; tüm bu toplantılarda ekolojik sorunlar ve bu sorunlara karşı üretilen çözümler sürdürülebilir kalkınmacılık ekseninde ortaya konmuştur.

Sürdürülebilir kalkınmanın neredeyse tüm dünyada kalkınma ve çevre politikalarına yön veren hakim anlayış olmasına rağmen, ekolojik sorunların boyutlarının gün geçtikçe artması ve ekolojik krizin giderek derinleşmesi, sürdürülebilir kalkınmacılığın iflası olarak değerlendirilebilir. Hali hazırda sürdürülebilir kalkınma anlayışı ekseninde oluşturulan çevre politikalarının ekolojik sorunların sebeplerini ortadan kaldıracak radikal dönüşümler öngörmediği de açıktır. Mevcut haliyle sürdürülebilirlik modeli, son kaynakların ya da rezervlerin sonuna kadar kullanımını ekolojik açıdan meşrulaştırmak için kullanılıyor izlenimi vermekte olup bu durum, kavramın tehlikeli bir yanılsama haline dönüşme ihtimalinin yüksek olduğunu göstermektedir (Radkau, 2017, s.508). Bu çerçevede önce mevcut üretim biçiminin öngördüğü toplumsal ve ekonomik yapının, sonra söz konusu yapılar çerçevesinde ortaya konan sürdürülebilir kalkınma anlayışının çok geç olmadan tartı̧̧maya açılması gerekmektedir.

Kapitalizm, doğa açısından sürdürülebilirliği destekleyen bir üretim biçimi olmaktan çok uzaktır. Kar elde etmek öncelikli amaç olarak kabul edildiğinde, bunun çevre üzerinde yarattığ kaçınılmaz olarak kabul etmek gerekmektedir. En basit mantıkla; su, hava ve toprak kirliliği, bu yegane amaç için oluşturulan üretim sistemlerinin doğal yan ürünleri haline gelmiştir. Kapitalist üretim ve değişim mantığı içinde, çevre üzerindeki bu olumsuz etkileri en aza indirecek bir iç mekanizma bulunmamaktadır (Magdotf, 2002, s.109). Sürdürülebilir 
kalkınma da mevcut üretim biçiminin dayand ı̆̆ piyasa ekonomisinin sürekli büyüme, tüketim, maksimum kar ve rekabet gibi temel yapı taşlarında bir değişiklik öngörmediğinden iddia edildiği gibi geleneksel kalkınma modellerinden radikal bir kopuşu işaret etmemektedir. Zira sürdürülebilir bir büyümenin gerçekleşebilmesi için günümüz büyüme modelinden nitelikli bir kopuş gerçekleşmesi gerekmektedir. Ekolojik bir topluma ulaşmak istiyorsak mevcut kalkınma modellerini gözden geçirmek, belki reddetmek ve kalkınmaya yeni tanımlamalar getirmek zorundayız. Bu da ancak ekonominin ekolojik bir şekilde yeniden yapılandırılmasıyla mümkün olabilecektir. Bunun için de ekolojik düşünce temelli yeni yaklaşımların benimsenmesi şarttır. Ekolojik düşünce, hangi biçimiyle olursa olsun mevcut üretim ve tüketim kalıplarını ciddi şekilde sorgulamakta ve ekolojik sorunların çözümü için mevcut sistem içinde toptan zihni bir dönüşümün gerçekleşmesi gerektiğini vurgulamaktadır. 


\title{
EXTENDED ABSTRACT
}

\section{Sustainable Development vs. Ecological Thought}

\author{
* \\ Hazal Ilgın Bahçeci - Kemal Görmez \\ Yozgat Bozok University - Ankara Hacı Bayram Veli University
}

The concept of sustainable development, first described in The Brundtland Report published in 1987, is built on the notion that a growth strategy is possible based on the protection of natural resources in a way that allows economic growth to continue in the future and this concept is one of the fundamental concepts that guide the environmental protection policies on the world scale today.

The aim of the study is to examine sustainable development within the framework of the political economy approach and to evaluate its share in the solution of ecological problems. Another aim of the study is to examine the claim, which is the starting point of sustainable development, intended the balance between development and environmental protection. In this framework, international meetings and legislations are not included in detail.

The study is a theoretical and interdisciplinary study based on literature, which is created by using relational research method. In the study, thesis, printed secondary sources such as books, articles, magazines and internet resources were used. A descriptive and interpretive research method was used to examine the relationship between sustainable development and the conditions of the period in which it emerged and to determine the role of the World Economic and political conditions in this mutual relationship, in particular. The understanding and the solution proposals of the understanding against ecological problems have been discussed within the framework of the economic political approach.

The emergence of the concept of sustainable development coincided with the capital accumulation crisis that the welfare state based on economic growth falls into in the 1970's. The growth crisis stemming from the nature of capitalism brought with it poverty and ecological deterioration. 
Ignoring the limitation of nature's capacity to reproduce itself and using it as a production input irreversibly increased the extent of the damage on nature and the environmental consequences of economic activities became more debatable. The increasing dimensions of ecological destruction created by the motto of economic growth brought to the agenda discussions on the limitation of natural resources which are raw material of the production process. Thus, the relationship between environment and development was dealt with in terms of economic approaches and started to become political in the framework of market economy. This process of politicization resulted in the emergence of a approach to balance the relationship between nature and economic growth within the current system and to create new policies to overcome the accumulation crisis of the system.

Another problem that accompanies the economic crisis was that the current development approach has become unsustainable. With the end of the colonial era after World War II, a new system was established on the basis of a growth-oriented development approach based on economic and technical assistance initiated by the developed countries towards the developing / underdeveloped countries during the reorganization of the international system. However, the current crisis brought about a search for a new understanding of development by making borrowing policies of underdeveloped / developing countries unsustainable, and the concept of sustainable development bagan to take shape in this frame.

In particular, the model of economic growth, which was shown as a solution to the problem of development of underdeveloped / developing countries, became impractical due to the crisis, strengthened the income inequality and accompanying political problems in these countries. In the 1970s, the necessity of a development approach, which included other concrete indicators, emerged besides economic growth. The next development notion has begun to be shaped by addressing social inequality on the basis of "lack of consumption" or "inequality of division of production". The search for balance between economic growth and the allocation of resources created led to the relative and absolute conceptualization of income distribution and a new understanding of development emerged that makes efforts to address the absolute needs of poor groups of the country. The main interests of this understanding are basic needs such as food, education, health etc. The most important result of this tendency is 
that poverty and social inequality are shown as a problem of distribution arising from the inequality of income distribution. The basic dynamics of capitalist mode of production are ignored.

The effort to overcome the crisis of capitalism in 1970's with the restructuring policies caused nature to become a secondary position in the face of development. In this process, nature, which is a "common property with a public nature", began to be shaped according to the exact competition conditions of the free market by the application of neo-liberal economic policies which can be applied in this process with the new developmentist approach, "poverty" was shown as one of the most important reasons for the destruction of nature and in this way, the destructive effect of the form of capitalist production on ecological destruction was made invisible to a great extent.

The perception that the balance between the environment and development can be achieved started to dominate through international organizations in this conditions. The concept of sustainable development was laid down by addressing the importance of protecting the environment for future generations, in the context of environmental and developmental relations at Stocholm Conference in 1972 and finally, the concept was placed on the agenda of the international public opinion in 1987.

The belief that sustainable growth is inevitable for the advancement of mankind has consumed resources and brought ecological problems to an irreversible dimension. At this point, sustainable development stands as an understanding based on the assumption that people have limited resources in the face of unlimited needs and that the current mode of production does not predict a change in the basic dynamics of continuous growth, competition, profit and consumption and that poverty can only come from technological progress. The concept has been subjected to serious criticism at the point that no progress has been made in the solution of ecological problems since 1987, and on the contrary, the dimensions of the problems are more visible each day and it is seriously examined by ecological thinking. 


\section{Kaynakça / References}

Başkaya, F. (2002). Kalkınma: Bir efsanenin sonu. Özgür Üniversite ForumuSürdürülebilemez Kalkınma, Temmuz-Eylül, 19, 7-26

Bozlağan, R. (2005). Sürdürülebilir gelişme düşüncesinin tarihsel arka planı. Sosyal Siyaset Konferansları Dergisi, 50, 1011-1028

Buyruk, H. (2016). Ekonomik kalkınma hedefinden bin yıl kalkınma hedeflerine: Eğitim- kalkınma ilişkisine dair bir çözümleme. Mülkiye Dergisi, 40 (1), 111-142

Chodorkoff, D. (2002). Kalkınmayı yeniden tanımlamak. (E. Köklü ve B. Tüfekçi, Çev.) Özgür Üniversite Forumu-Sürdürülebilemez Kalkınma, Temmuz-Eylül, 19, 113-121

Cleaver, H. (2002). Doğa, neoliberalizm ve sürdürülebilir kalkınma: Charybdıs ve Scylla arasında. (M. Beyazıt, Çev.) Özgür Üniversite Forumu-Sürdürülebilemez Kalkımma, Temmuz-Eylül, 19, 54-72

Çelik, M. ve Dağ, M. (2017). Kapitalist iktisadi düşüncenin geçirdiği dönüşümler üzerine bir değerlendirme. Bitlis Eren Üniversitesi İktisadi Ve İdari Bilimler Fakültesi Akademik İzdüşüm Dergisi, 2(3), 50-70

Dünya Çevre ve Kalkınma Komisyonu (1987). Ortak geleceğimiz, (B. Çorakçı, Çev.) Ankara: Türkiye Çevre Sorunları Vakfı Yayınları

Estava, G. (2007). Kalkınma. W. Sachs, (Der.), Kalkınma sözlü̈̆ü: Bir iktidar olarak bilgiye giriş.(O. Etiman, Çev.) içinde (ss. 17-50). Ankara: Maki Basım

Görmez, K. (2018). Çevre sorunları. Ankara: Nobel Yayınevi

Hirschman, A. O. (2015). Kalkınma iktisadr: Yükselişi ve gerilemesi. (S. Öztürk, Çev.), F. Şenses,(Der.) İstanbul: İletişim Yayınları

Illich, I. (2007). İhtiyaçlar. W. Sachs, (Der.), Kalkınma sözlüğ̈̈: Bir iktidar olarak bilgiye giriş. (O. Etiman, Çev.) içinde (ss. 157-180). Ankara: Maki Basım

Kaplan, A. (1999). Küresel çevre sorunları ve politikaları. Ankara: Mülkiyeliler Birliği Vakfı Yayınları

Kılıç, S. (2012). Sürdürülebilir kalkınma anlayışının ekonomik boyutuna ekolojik bir yaklaşım. İ. Ü. Siyasal Bilgiler Fakültesi Dergisi, 47, 201226 
Magdotf, H. (2002). Kapitalizmin ikiz krizleri: Ekonomik ve ekolojik. (E. Aydoğdu, Çev.) Özgür Üniversite Forumu-Sürdürülebilemez Kalkınma, 19, 107-112

Meadows, D. H, Meadows, D. L., Landers, J., Behrens, W. W. (1972). The limits to growth: A report for The Club Of Rome's project on the predicament of mankind. Newyork: Universe Books

Mengi, A. ve Algan, N. (2003). Küreselleşme ve yerelleşme çağında bölgesel sürdürülebilir gelişme. Ankara: Siyasal Kitabevi

Özlüer, F. (2007). Sürdürülebilir kalkınmanın ekonomi politiği. Dosya 05 Sürdürülebilirlik: Kent ve Mimarlık, Bülten 51, Haziran, 4-13

Radkau, J. (2017). Doğa ve iktidar: Global bir çevre tarihi. (N. Güder, Çev.). İstanbul: Türkiye İş Bankası Kültür Yayınları

Şahin, Ü. (2004). Bir truva atı olarak sürdürülebilir kalkınma. Üç Ekoloji Dergisi, 2, 195-206

United Nations (1972). Report of The United Nations Conference on The Human Environment. 5-16 June, Stockholm

Yaylı, H. (2011). Sürdürülebilir kalkınmanın sürdürülebilirliği. 38. Uluslararası Asya ve Kuzey Afrika Çalışmaları Kongresi Çeore, Kentleşme Sorunları ve Çözümleri Bildiriler Kitabı içinde (ss. 917-935). C. II, Ankara: Atatürk Kültür Dil ve Tarih Yüksek Kurumu Yayınları

\section{Kaynakça Bilgisi / Citation Information}

Bahçeci, H. I. ve Görmez, K. (2019). Sürdürülebilir kalkınma Vs. ekolojik düşünce. OPUS-Uluslararası Toplum Araştırmaları Dergisi, 10(17), 2299-2323. DOI: 10.26466/opus.537418 